\title{
Investigating the role of small, acid-soluble spore proteins (SASPs) in the resistance of Clostridium perfringens spores to heat Deepa Raju1,2, Michael Waters ${ }^{1,2}$, Peter Setlow ${ }^{3}$ and Mahfuzur R Sarker*1,2
}

\begin{abstract}
Address: ${ }^{1}$ Department of Biomedical Sciences, College of Veterinary Medicine, Oregon State University, Corvallis, Oregon 97331, USA, ${ }^{2}$ Department of Microbiology, College of Science, Oregon State University, Corvallis, Oregon 97331, USA and ${ }^{3}$ Department of Molecular, Microbial and Structural Biology, University of Connecticut Health Center, Farmington, CT 06030, USA
\end{abstract}

Email: Deepa Raju - rajud@onid.orst.edu; Michael Waters - mswaters@usc.edu; Peter Setlow - setlow@nso2.uchc.edu; Mahfuzur R Sarker* - sarkerm@oregonstate.edu

* Corresponding author

Published: 08 June 2006

BMC Microbiology 2006, 6:50 doi:10.1 |86/147|-2180-6-50

This article is available from: http://www.biomedcentral.com/I47I-2180/6/50

(c) 2006 Raju et al; licensee BioMed Central Ltd.

This is an Open Access article distributed under the terms of the Creative Commons Attribution License (http://creativecommons.org/licenses/by/2.0), which permits unrestricted use, distribution, and reproduction in any medium, provided the original work is properly cited.
Received: 19 April 2006

Accepted: 08 June 2006

\begin{abstract}
Background: Clostridium perfringens type $A$ food poisoning is caused by enterotoxigenic $C$. perfringens type $A$ isolates that typically possess high spore heat-resistance. The molecular basis for $C$. perfringens spore heat-resistance remains unknown. In the current study, we investigated the role of small, acid-soluble spore proteins (SASPs) in heat-resistance of spores produced by $C$. perfringens food poisoning isolates.
\end{abstract}

Results: Our current study demonstrated the presence of all three SASP-encoding genes (ssp I, 2 and 3 ) in five surveyed $C$. perfringens clinical food poisoning isolates. $\beta$-Glucuronidase assay showed that these ssp genes are expressed specifically during sporulation. Consistent with these expression results, our study also demonstrated the production of SASPs by $C$. perfringens food poisoning isolates. When the heat sensitivities of spores produced by a ssp3 knock-out mutant of a $C$. perfringens food poisoning isolate was compared with that of spores of the wild-type strain, spores of the $s s p 3$ mutant were found to exhibit a lower decimal reduction value $\left(D\right.$ value) at $100^{\circ} \mathrm{C}$ than exhibited by the spores of wild-type strain. This effect was restored by complementing the ssp3 mutant with a recombinant plasmid carrying wild-type ssp3, suggesting that the observed differences in $D$ values between spores of wild-type versus ssp3 mutant was due to the specific inactivation of $s s p 3$. Furthermore, our DNA protection assay demonstrated that $C$. perfringens SASPs can protect DNA from DNase I digestion.

Conclusion: The results from our current study provide evidences that SASPs produced by $C$. perfringens food poisoning isolates play a role in protecting their spores from heat-damage, which is highly significant and relevant from a food safety perspective. Further detailed studies on mechanism of action of SASPs from $C$. perfringens should help in understanding the mechanism of protection of $C$. perfringens spores from heat-damage.

\section{Background}

Clostridium perfringens is a gram-positive, spore-forming, anaerobic bacterium that has long been recognized as a significant cause of histotoxic and gastrointestinal (GI) diseases in both humans and animals $[1,2]$. C. perfringens isolates can be classified into one of five types (A through 
E) based upon their ability to produce alpha-, beta-, epsilon- and iota-toxin [2]. Although enterotoxin (CPE)-producing $C$. perfringens type $A$ isolates represent $<5 \%$ of global $C$. perfringens population, these bacteria are very important human GI pathogens, causing C. perfringens type A food poisoning and non-food-borne GI diseases [1]. Substantial experimental and epidemiological evidence $[1,3]$ now indicates that CPE plays a major role in the development of GI symptoms in cases of C. perfringens-associated food poisoning and non-food-borne GI diseases. In addition to producing CPE, C. perfringens food poisoning isolates have the ability to form heat-resistant spores, which can survive boiling for an hour or longer $[1,4,5]$. The possession of high spore heat-resistance facilitates the survival of $C$. perfringens spores in primary food vehicles (such as meat and poultry products) where, in the presence of appropriate nutrients, dormant spores are reverted to vegetative cells and multiply, and then cause food-borne illness after consumption of these contaminated foods [1].

The molecular basis for C. perfringens spore heat-resistance remains unknown. However, since small, acid-soluble spore proteins (SASPs) from Bacillus subtilis can protect their spores from damage by heat and other environmental factors [6-8], it is very likely that $C$. perfringens SASPs play a similar role. Spores of Bacillus and Clostridium species contain a number of SASPs of molecular weight 5-7 $\mathrm{kDa}$, which comprise $10-20 \%$ of the total spore protein [8]. These proteins are classified into two groups based on their primary sequence, an $\alpha / \beta$-type and a $\Upsilon$-type [8]. The B. subtilis $\alpha / \beta$-type SASPs are encoded by multiple genes and comprise a large protein family whose amino acid sequences are very highly conserved within and between species [8]. The B. subtilis $\alpha / \beta$-type SASPs are non-specific DNA binding proteins which saturate the spore chromosome and protect spore DNA from damage caused by heat, UV radiation, and peroxidase [9-12]. Although an enormous number of studies on the role of SASPs in $B$. subtilis spore resistance have been carried out, nothing is known about the role of $C$. perfringens SASPs. However, the advance towards understanding the role of SASPs in $C$. perfringens spore resistance is emerging from some old studies [13-15] which revealed the existence of multiple $\alpha / \beta$-type, but not $\Upsilon$-type, SASPs in Clostridium species. Three genes (ssp1, 2 and 3 ) coding for $\alpha / \beta$-type SASPs have been cloned and nucleotide sequenced from $C$. perfringens old strains $[16,17]$. Interestingly, only these three $s s p$ genes, compared to at-least 7 ssp genes in B. subtilis [8], were identified in the genome of $C$. perfringens strain 13 [18]. However, the presence and expression of these ssp genes in recent clinical $C$. perfringens food poisoning isolates and their role in spore heat-resistance remains unknown.
In the current study, we investigated the genetics and expression of ssp genes in C. perfringens clinical food poisoning isolates. Our study also prepared an isogenic ssp3 knock-out mutant of a C. perfringens type A food poisoning isolate. The heat sensitivities of spores produced by ssp3 knock-out mutant was compared with that of spores of the wild type strain. The results from these experiments now provide evidence that $C$ perfringens SASPs play a role in spore heat-resistance.

\section{Results \\ PCR screening and comparison of ssp ORFs in C. perfringens food poisoning isolates}

We first subjected our collection of $C$. perfringens food poisoning isolates to ssp-specific PCR analysis to determine whether most, or all, cpe-positive food poisoning isolates carry all three ssp genes (ssp1,2 and 3). Control PCRs were run using template DNA prepared from a known ssp-positive C. perfringens strain 13 [18]. When template DNA isolated from each of our five surveyed clinical C. perfringens food poisoning isolates was subjected to this same ssp PCR analysis, PCR products of 239-, 306-, and 522-bp were invariably obtained (see Fig. 1 for representative results). These results are in consistent with the known presence (Fig. 1) of all three ssp ORFs in the genome of the C. perfringens strain 13 [18].

The nucleotide sequencing analyzes revealed (data not shown) that no mutations or termination codons were found in the ssp1, 2 or 3 ORF sequences of our five sur-

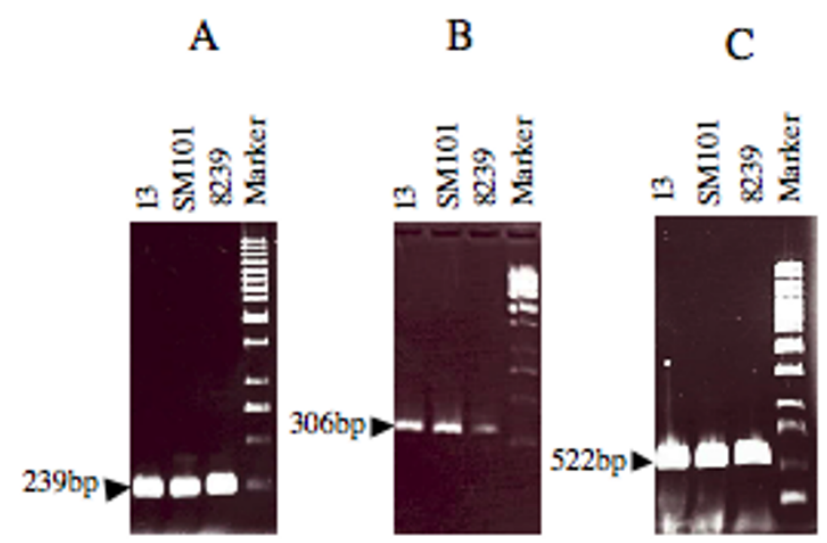

\section{Figure I}

ssp PCR analysis of $C$. perfringens food poisoning isolates. Representative results of a PCR assay with primers designed to amplify ssp I (A), ssp2 (B) or ssp3 (C) specific PCR products. Results are shown for control strain I3 (a known sspl, 2 and 3-positive strain) and representative food poisoning isolates SMIOI and NCTC8239. Marker indicates the migration of DNA size markers (Gene Ruler ${ }^{\mathrm{TM}}$ I-kb ladder; Fermentas). 
veyed isolates that encode proteins of 60-, 59- or 60-aa, respectively. The ssp 1, 2 or 3 ORF sequences and also the upstream promoter sequences are highly conserved in all our surveyed food poisoning isolates and matches exactly with previously published sequences $[16,18]$.

\section{Evaluation of expression of ssp genes in C. perfringens food poisoning isolates}

To examine the expression of ssp genes, the putative promoter regions of ssp1, 2, or 3 from $C$. perfringens food poisoning isolate SM101 was fused to E. coli gusA. These sspgusA fusion constructs were introduced into wild-type SM101 and $\beta$-glucuronidase (GUS) activity was measured during vegetative and sporulation growth. A promoterless gusA construct was used as a negative control to ensure the specificity and reliability of the assay (Data not shown).

When GUS assay was performed on SM101 carrying pSG12 (ssp1-gusA), pSG22 (ssp2-gusA) or pSG32 (ssp3gusA), no significant expression of $s s p 1,2$ or 3 was observed in vegetative cells (Fig. 2). However, SM101 carrying ssp1-, 2-or 3-gusA showed GUS activity during sporulation. The ssp1-gusA expression began at $\sim 4 \mathrm{~h}$ after induction of sporulation, with maximum specific activity attained at $\sim 12 \mathrm{~h}$ after induction of sporulation (Fig. 2). Both ssp2-gusA and ssp3-gusA fusions were expressed beginning at $\sim 2 \mathrm{~h}$ after induction of sporulation, with maximum specific activity attained $\sim 6 \mathrm{~h}$ after induction of sporulation (Fig. 2). Collectively, these results suggest that all three ssp genes are expressed during sporulation, but not during vegetative growth.

To analyze the sporulation-dependent expression of ssp genes further, we examined the expression of $s s p 1-$, 2- or 3-gusA fusion in a spo0A mutant of C. perfringens. The rationale for using $s p o 0 A$ mutant is that, if $s s p$ expression is truly dependent on sporulation, ssp-gusA fusions would not be expressed in sporulation-deficient spo0A mutant of C. perfringens [19]. The ssp-gusA fusion constructs pSG12 (ssp1-gusA), pSG22 (ssp2-gusA) and pSG32 (ssp3-gusA) were introduced into $C$. perfringens spo0A mutant strain IH101 and GUS activity was measured during sporulation growth. As shown in Fig 2, no detectable GUS activity was obtained with sporulating cultures of IH101 carrying ssp1,2, and 3-gusA fusions, confirming that the expression of ssp genes in $C$. perfringens are dependent on spo0A expression and sporulation.

SASP production by C. perfringens food poisoning isolates Having obtained evidence that all three ssp genes are expressed in $C$. perfringens food poisoning isolates, we next examined whether these isolates can, in fact, produce SASPs. When acid-extracts of spores from representative C. perfringens food poisoning isolates SM101 (Fig. 3) and NCTC8239 (data not shown) were analyzed by polyacrylamide gel electrophoresis at low $\mathrm{pH}$, multiple protein bands were observed. Western blot analysis, using antibodies against SspC of B. subtilis, detected SspC-specific immunoreactivity in acid-extracts of spores from SM101 and NCTC8239 (Fig. 3 and data not shown). These results
A

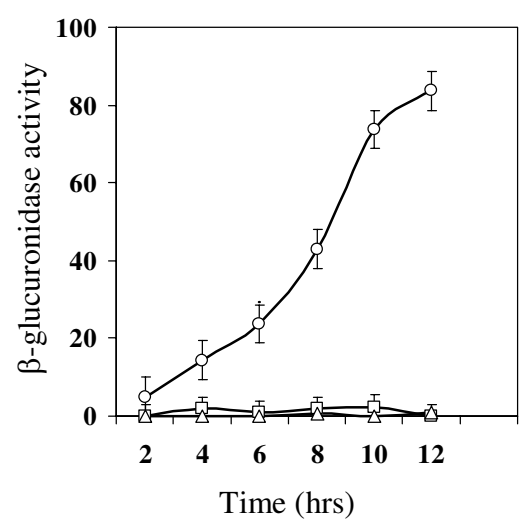

B

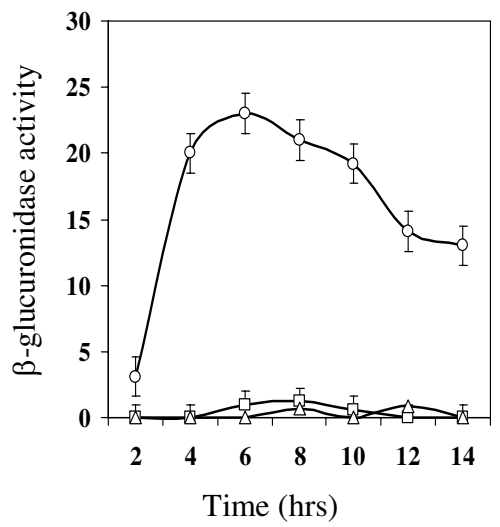

$\mathrm{C}$

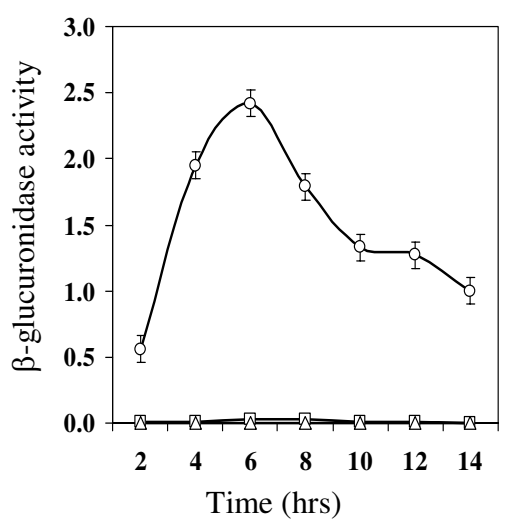

Figure 2

Expression of ssp I-gusA (A), ssp2-gusA (B) and ssp3-gusA (C) fusions in C. perfringens wild-type SMI0I grown in vegetative ( $\square$ ) and sporulation $(O)$ medium, and in spoOA mutant IHIOI grown in sporulation medium $(\Delta)$. $\beta$-glucuronidase activity (in Miller Units) was calculated as previously described $[26,28]$. Data represents the average of three independent experiments. 


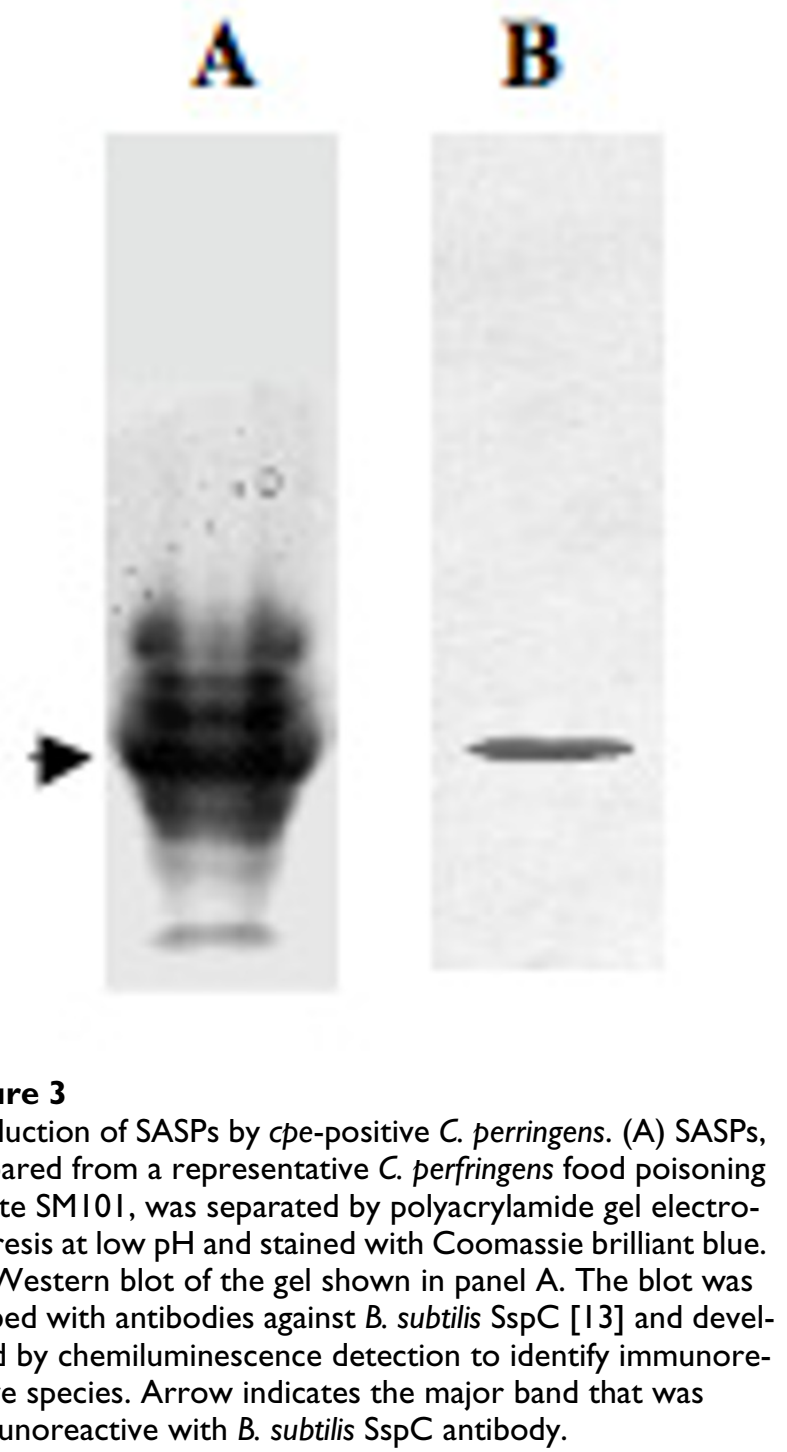

indicated that $C$. perfringens food poisoning isolates can produce SASPs.

\section{Creation of ssp knock-out mutants}

To evaluate the role of SASPs in spore heat-resistance, we attempted to introduce knock-out mutations into each ssp gene. The mutator plasmid pDR63, pDR27 or pMRS62, carrying mutated allele $\Delta s s p 1::$ catP, $\Delta s s p 2::$ catP and $\Delta s s p 3:: c a t P$, respectively, was introduced into $C$. perfringens strain SM101 by electroporation, and $\mathrm{Em}^{\mathrm{r}} \mathrm{Cm}^{\mathrm{r}}$ transformants were selected. As a positive control of transformation, the C. perfringens-E. coli shuttle plasmid pJIR751 encoding $\mathrm{Em}^{\mathrm{r}}$ was included. The $\mathrm{Em}^{\mathrm{r}} \mathrm{Cm}^{\mathrm{r}}$ transformants were obtained at $\sim 1000$-fold less frequencies than that of pJIR751-derived $\mathrm{Em}^{\mathrm{r}}$ transformants, which was expected because mutator plasmids pDR63, pDR27 and pMRS62 have no origin of replication for $C$. perfringens. The single cross-over event of homologous recombination was confirmed by PCR using each ssp-specific primers (data not shown). One transformant for each mutator plasmid was grown in the absence of both Em and $\mathrm{Cm}$, and a double crossover event between each wild-type ssp and the respective mutated $\Delta s s p:: c a t P$ allele was screened by selecting colonies for $\mathrm{Cm}^{\mathrm{r}}$ and $\mathrm{Em}^{\mathrm{s}}$ phenotypes. After screening of 2,500 colonies from SM101(pMRS62) culture, we obtained one putative clone showing a $\mathrm{Cm}^{\mathrm{r}}$ and $\mathrm{Em}^{\mathrm{s}}$ phenotype. This putative ssp3 mutant was designated as DR101. However, no $\mathrm{Cm}^{\mathrm{r}}$ and $\mathrm{Em}^{\mathrm{s}}$ clone was obtained after screening of $>3,000$ colonies from each of SM101(pDR27) and SM101(pDR63) culture. Our three repeated attempts using SM101(pDR63) and SM101(pDR27) transformants from three independent electroporations were failed to isolate spp1 and ssp2 mutant, respectively.

\section{Confirmation of DRIOI as ssp3 knock-out mutant}

Inactivation of ssp3 in DR101 was first demonstrated by PCR analysis (Fig. 4A) using ssp3-specific primers. An $\sim 4.1$-kb fragment carrying ssp3 was amplified from DNA
A

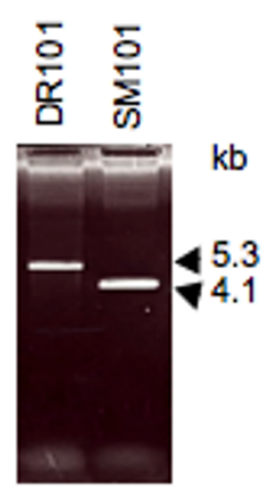

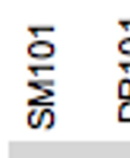
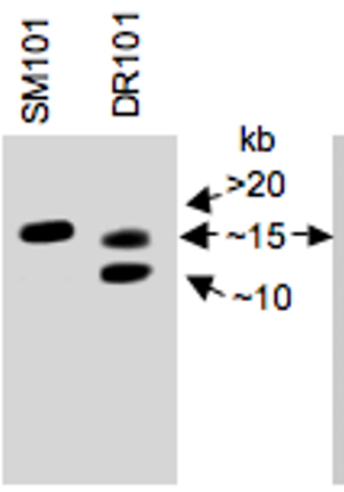

ssp 3 probe
B

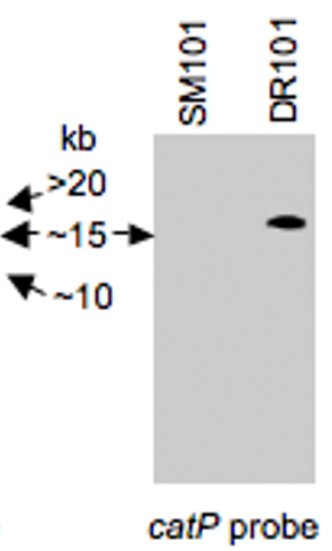

\section{Figure 4}

Molecular analysis of ssp3 knock-out mutant. (A) PCR analysis of the total DNAs from $C$. perfringens wild-type and ssp3 mutant. Total DNA isolated from wild type SMIOI and the ssp3 mutant DR IOI strains was subjected to PCR analysis using ssp3-specific primer pair CPPI3/CPPI6. (B) Southern hybridization analysis of total DNAs from $C$. perfringens wildtype and ssp3 mutant. Two identical Southern blots were prepared using Hpal-digested DNAs from wild-type (SMIOI) and ssp3 mutant (DRIOI) and probed separately with either ssp-specific or catP-specific DIG-labeled probes. The migration of the hybridizing band derived from each strain is indicated between the two blots. 
of wild-type strain SM101. In contrast, an 5.4-kb PCR product was obtained from DNA of mutant strain DR101. These PCR results are consistent with the wild-type ssp3 gene in DR101 having been replaced with the mutated allele, carrying an extra $\sim 1.3-\mathrm{kb}$ catP-containing fragment.

Southern blot analyses showed that a single HpaI-digested DNA fragment from wild-type strain SM101 hybridized with ssp3-specific probe (Fig. 4B). However, two hybridizing bands were observed with DNA from mutant strain, DR101 (Fig. 4B). This profile is consistent with results expected since the $\sim 1.3-\mathrm{kb}$ catP-containing fragment has an internal HpaI site. The catP-specific probe hybridized with an 15-kb HpaI fragment of DR101 DNA, but as expected, no hybridizing band was observed with DNA from wild type SM101 (Fig. 4B). These results further confirmed that wild-type ssp3 gene in DR101 having been replaced with $\Delta s s p 3::$ catP allele.

\section{Sporulation and CPE production by ssp3 mutant}

We first compared the sporulation capability of the $s s p 3$ mutant against that of its wild-type. Both the mutant strain DR101 and wild-type strain SM101 exhibited significant sporulation, i.e., refractile endospores were visualized by phase-contrast microscopy after 8 h growth in DS medium (data not shown). When we compared the CPE producing capabilities of the wild-type strain SM101 and ssp3 knock-out mutant DR101, an 35-kDa CPE-specific immunoreactive band was detected in Western blots of lysates prepared from sporulating cultures of both SM101 and DR101 (data not shown). Quantitative analyses demonstrated similar level of CPE production in both SM101 and DR101 (data not shown).

\section{Comparison of the heat sensitivities of spores produced by C. perfringens food poisoning isolate carrying wild-type versus knock-out ssp3}

In order to determine whether $s s p 3$ has any role in spore heat-resistance, we performed experiments to evaluate the heat sensitivities of spores produced by $C$. perfringens wild-type and ssp3 mutant. Representative thermal death curves obtained at $100^{\circ} \mathrm{C}$ for heat-shocked sporulating cultures of wild-type SM101 and ssp3 mutant DR101 are shown in Fig. 5. From the Fig. 5 results, we calculated that spores of SM101, carrying the wild-type ss 33 gene, had a $D$ value of $\sim 90 \mathrm{~min}$ at $100^{\circ} \mathrm{C}$, while spores of DR101, an isogenic ssp3 mutant, had a $D$ value of $\sim 60 \mathrm{~min}$. To further confirm our results, three additional $D$ values at $100^{\circ} \mathrm{C}$ for heat-shocked sporulating cultures of DR101 and SM101 were determined using three independent thermal death curves (data not shown). These results demonstrated that spores produced by the ssp3 mutant had, on average, approximately 0.5 -fold-lower $D$ value at $100^{\circ} \mathrm{C}$ than spores produced by the wild-type strain (the difference was statistically significant at $P=0.001$ ).

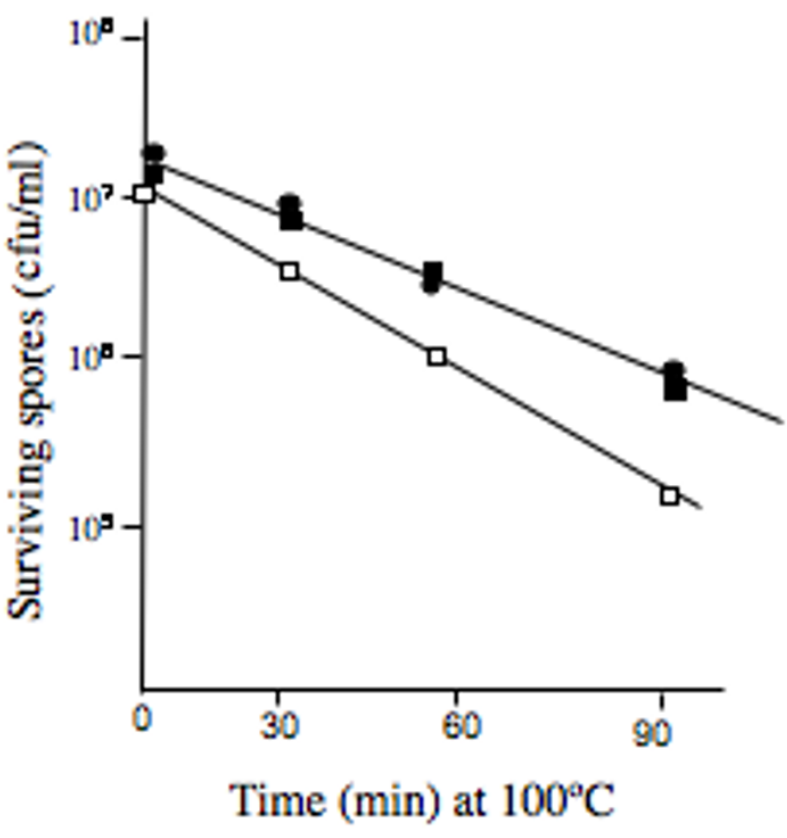

Figure 5

Thermal death curves for sporulating cultures of wild-type SMIOI (O), ssp3 mutant DRIOI ( $\square$ ), and complemented DRIOI(pDRI8) ( $\square$ ) strains. The data is the result of a representative experiment; these results were highly reproducible (data not shown).

In order to determine whether the observed differences in $D$ values between spores of SM101 and spores of DR101 was due to the specific inactivation of $s s p 3, D$ value was determined at $100^{\circ} \mathrm{C}$ for heat-shocked sporulating cultures of complemented strain DR101(pDR18). As calculated from Fig. 5, spores produced by DR101(pDR18) had a wild-type level $D$ value i.e., $\sim 90 \mathrm{~min}$ at $100^{\circ} \mathrm{C}$. This finding was confirmed by three independent experiments. Collectively, our results indicated that the reduced heatresistance of spores produced by the ssp3 knock-out mutant was caused by the specific inactivation of $s s p 3$.

\section{Protection of plasmid DNA against DNase I}

Since B. subtilis SASPs have been shown to bind doublestranded DNA and protect against DNase cleavage [20], we wondered whether $C$. perfringens SASPs can do the same. We purified total SASPs from C. perfringens SM101 (Fig. 3 ) and performed SASP-DNA binding assay by measuring the ability of SASPs to protect plasmid (pJIR751) DNA from DNase I digestion. As shown in Fig. 6., when pJIR751 DNA was incubated with DNase I, no DNA band was observed after agarose gel elctrophoresis (lanes 2 and 4 ), indicating that DNase I is enzymatically active and completely digested the pJIR751 DNA. However, when pJIR751 DNA was incubated with $C$. perfringens SASPs 


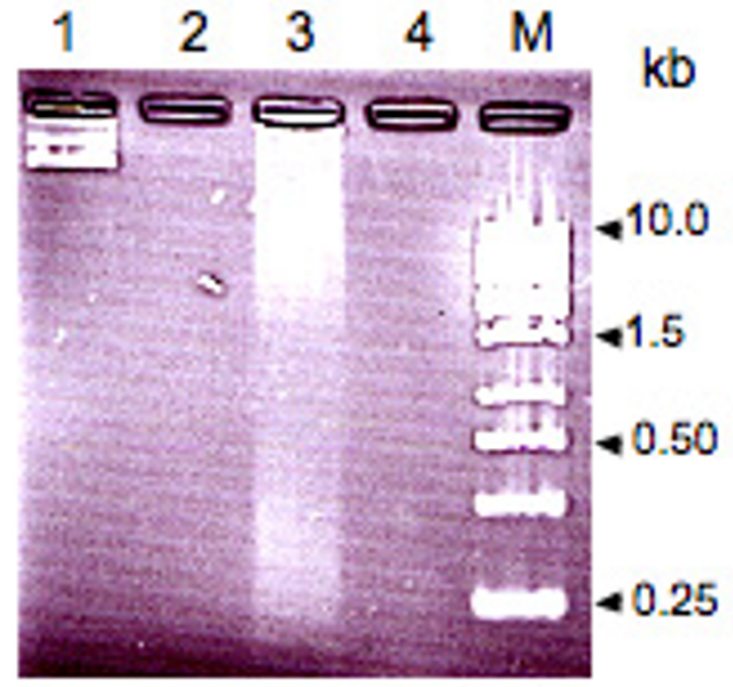

\section{Figure 6}

Protection of DNA against DNase I digestion by SASPs binding. The pJIR75 I DNA was incubated alone (lane I), with DNase I (lane 2), with SASPs and DNase I (lane 3) or DNase $I$ in the presence of $8 M$ urea (lane 4). $M$ indicates the migration of DNA size markers (Gene Ruler ${ }^{\mathrm{TM}}$ I-kb ladder; Fermentas). The results are from representative experiments; these results were highly reproducible (data not shown).

prior to DNase I treatment, discrete DNA fragments remained after DNase I treatment (lane 3). Furthermore, the incomplete digestion of SASP-treated DNA was not due to the inhibition of DNase I activity by urea because the enzyme was completely functional in the presence of $8 \mathrm{M}$ urea (Fig. 6, lane 4) that was used to dissolve SASPs. Collectively, these results indicated that SASPs protected plasmid DNA against DNase I digestion. Similar results were obtained in our three independent experiments (see Fig. 6 for representative results). This observation indicated that the function of SASPs in C. perfringens food poisoning isolates is similar to that in B. subtilis, i.e., they protect spores from heat-damage by binding to spore DNA.

\section{Discussion}

C. perfringens type A food poisoning, which currently ranks as the third most commonly reported food-borne disease in the United States [1], is caused by enterotoxigenic $C$. perfringens type A isolates that typically possess high spore heat-resistance $[1,4]$. The possession of high spore heat-resistance favors the survival of $C$. perfringens food poisoning isolates during incomplete cooking or inadequate holding of foods, which are the two major factors contributing to $C$. perfringens type A food-borne illness [1]. However, the molecular basis for $C$. perfringens spore heat-resistance remains unknown. In the current study, we hypothesized that SASPs produced by C. perfringens food poisoning isolates can play a role in the resistance of their spores to heat.

Our current study demonstrated the presence of all three $s s p$ genes in a large number of clinical C. perfringens food poisoning isolates. Nucleotide sequencing revealed that the ssp ORFs in our surveyed isolates are intact, i.e., no mutations or premature termination codons were detected in the ORFs. Although previous studies [16,17] reported the presence of ssp1, 2 and 3 in C. perfringens laboratory strains, to our knowledge, our study is the first to compare all three ssp ORFs between a large number of clinical cpe-positive $C$. perfringens food poisoning isolates. The deduced amino acid sequence of SASPs from our surveyed C. perfringens food poisoning isolates are identical to that of the $C$. perfringens SASPs published earlier $[16,17]$ and homologous to $\alpha / \beta$-type SASPs of $B$. subtilis [8] indicating that the ssp ORFs present in food poisoning isolates are indeed $s s p$ genes.

This study report evidences that the ssp genes present in $C$. perfringens food poisoning isolates are functional. Our GUS assay showed that ssp1, 2 and 3 from a food poisoning isolate SM101 were expressed during sporulation, but not during vegetative growth, and expression begins $~ 3-4$ $h$ after induction of sporulation. These results suggest that the mechanism of regulation of $C$. perfringens SASPs may be similar as that of $B$. subtilis. In B. subtilis, SASPs synthesis begins 3-4 h into sporulation, when all three major SASPs are synthesized in parallel [8]. The differential expression of ssp genes (Fig. 2) can not be explained by the differences in ribosome binding sites (rbs) because the putative rbs is highly conserved among the three ssp genes (data not shown). Further support for the sporulationdependent expression of $C$. perfringens ssp genes came from our observations that no GUS activity was detected in spo0A mutant IH101 carrying ssp1-, 2- or 3-gusA fusion. Consistent with these expression results, our study also provides evidence that $C$. perfringens food poisoning isolates can, in fact, produce SASPs. The multiple protein bands obtained in our study from acid extracts of spores produced by food poisoning isolates (Fig. 3) were also observed previously [13] in acid extracts of spores produced by $C$. perfringens NCTC9268. The identity of these acid-soluble spore proteins as SASPs was confirmed by Western blot analyses using B. subtilis SspC antibody (Fig. 3 ). The single immunoreactive band observed in Western blot can be explained by the fact that $C$. perfringens ssp1, 2 and 3 are highly homologous (>90\%) to each other and encode similar sized proteins (59-60 aa). Collectively, the presence and expression of ssp genes in C. perfringens food poisoning isolates, which possess high spore heat-resistance as indicated in a previous study [4], significantly 
strengthen the hypothesis that SASPs are associated with heat-resistance of spores produced by these isolates.

The present study's most significant finding is the presentation of the first genetic evidence that $C$. perfringens SASPs play a role in heat-resistance of spores produced by $C$. perfringens. The inactivation of $s s p 3$ significantly affected the heat-resistance of spores produced by a food poisoning isolate SM101. Our findings that i) spores of $s s p 3$ knockout mutant exhibited lower heat-resistance than that of the spores of wild type and ii) reversion of this effect by complementing the mutant with a recombinant plasmid carrying wild type ssp3, provided direct genetic evidence supporting the strong linkage between the production of SASPs and the resistance of spores to heat. The slight reduction of $D$ value in spores of $s s p 3$ mutant compared to the $D$ value of spores of wild-type can be explained by the presence of the functional $s s p 1$ and $s s p 2$ genes in $s s p 3$ mutant strain DR101. Our DNA protection assay also supports the role of $C$. perfringens SASPs in spore heat-resistance by demonstrating that $C$. perfringens SASPs, like $B$. subtilis SASPs [20], can protect plasmid DNA from DNase I digestion. Further studies on characterization of SASPDNA binding and the effect of this binding on plasmid topology should help in understanding the mechanism of interaction between DNA and SASPs from C. perfringens.

To our knowledge, this report represents the first successful study involving the construction of a C. perfringens ssp knock-out mutant. The greatest challenge faced in our $s s p$ knock-out study was the lack of an easy screening method for the second cross-over event. Although in our first attempt, using the double-antibiotic selection strategy [3], we were able to isolate ssp 3 knock-out mutant, our three similar independent attempts were failed to isolate ssp1 and $s s p 2$ mutant. The reasons for these failures can not be explained by the lack of sufficient amount of homologous DNA in mutator plasmids [21] because, both pDR62 and pDR27 carry at-least 1.4-kb homologous DNA located on either side of the insertionally inactivated ssp gene that should be sufficient to allow double-reciprocal crossover event [19]. It is also unlikely that incorporation of catP in $s s p 1$ or $s s p 2$ can cause polar effect on the downstream gene whose expression is essential for the survival of $C$. perfringens cells because our nucleotide sequencing analyses (data not shown) demonstrated that neither ssp1 nor ssp2 forms an operon with any downstream gene in the genome of SM101. Therefore, further research is needed to identify the relevant obstacles for isolating $s s p 1$ and $s s p 2$ mutants.

\section{Conclusion}

The current study demonstrated that i) all three ssp genes are present and expressed in a large number of clinical $C$. perfringens food poisoning isolates, ii) $s s p 3$ knock-out mutant of $C$. perfringens food poisoning isolate possess lower spore-heat resistance compared to that of its parent strain and this effect could be restored by complementing the mutant with wild-type $s s p 3$ gene, and iii) SASPs from C. perfringens food poisoning isolate can protect DNA from DNase I digestion. Collectively, these results support our initial hypothesis that SASPs produced by C. perfringens food poisoning isolates can play a role in resistance of their spores to heat. These findings are highly significant and relevant from a food safety perspective because the possession of high spore heat-resistance favors the survival of $C$. perfringens food poisoning isolates in primary food vehicles (such as, meat and poultry products) contributing to C. perfringens food-borne illnesses [1]. Further detailed studies on mechanism of action of SASPs from $C$. perfringens should help in understanding the mechanism of protection of $C$. perfringens spores from damage caused by heat and other environmental stresses.

\section{Methods}

\section{Bacterial strains and growth conditions}

C. perfringens strains and plasmids used in this study are listed and described in Table 1 . Starter culture $(10 \mathrm{ml})$ of each $C$. perfringens isolate was prepared by overnight growth at $37^{\circ} \mathrm{C}$ in fluid thioglycollate broth (FTG) (Difco) as described previously [22]. For DNA isolation, an aliquot $(0.2 \mathrm{ml})$ of each FTG culture was inoculated into $10 \mathrm{ml}$ of TGY broth (3\% Trypticase, $2 \%$ glucose, $1 \%$ yeast extract, $0.1 \%$ cysteine [22]) which was then incubated at $37^{\circ} \mathrm{C}$ for $18 \mathrm{~h}$ without shaking. For selecting $C$. perfringens transformants carrying recombinant plasmids, C. perfringens cultures were plated on Brain Heart Infusion agar plate containing erythromycin $(50 \mu \mathrm{g} / \mathrm{ml})$ or chloramphenicol $(20 \mu \mathrm{g} / \mathrm{ml})$ and incubated at $37^{\circ} \mathrm{C}$. Sporulating cultures of $C$. perfringens were prepared by inoculating $0.2 \mathrm{ml}$ of starter FTG medium culture into 10 $\mathrm{ml}$ of Duncan-Strong (DS) sporulating medium [22], which was then incubated for $24 \mathrm{~h}$ at $37^{\circ} \mathrm{C}$. The presence of sporulating cells in each DS medium culture was confirmed by phase-contrast microscopy $[19,23]$.

\section{ssp-specific PCR analysis}

Total C. perfringens DNA was isolated from the overnight TGY medium cultures using a previously described protocol $[4,24]$. The isolated DNA was then subjected to $s s p$ PCR analysis using primers specific for each of the ssp 1,2 or 3 genes as designed based on C. perfringens strain 13 genome sequence [18] (Table 2). Although the SASPs are multigene family proteins and the coding regions of three C. perfringens ssp are very similar, no sequence similarities were found between the flanking regions of these genes $[16,18]$. Therefore, each PCR primer pairs (Table 2) designed from the flanking region of each of the ssp gene amplified the respective ssp ORF sequences. These PCRs utilized $100 \mathrm{ng}$ of template DNA, 25 pM of each primer, 
Table I: Bacterial strains and Plasmids used in this study

\begin{tabular}{|c|c|c|}
\hline Bacterial strain/Plasmid & Relevant Characteristics ${ }^{a}$ & Sources or Reference \\
\hline \multicolumn{3}{|l|}{ C. perfringens } \\
\hline SMIOI & $\begin{array}{l}\text { Electroporatable derivative of food poisoning } \\
\text { type A isolate, NCTC } 8798, \text { carries a } \\
\text { chromosomal cpe }\end{array}$ & [28] \\
\hline NCTC8239 & $\begin{array}{l}\text { Food poisoning type } \mathrm{A} \text { isolate carrying a } \\
\text { chromosomal cpe }\end{array}$ & {$[30]$} \\
\hline FDI04I & $\begin{array}{l}\text { Food poisoning type } \mathrm{A} \text { isolate carrying a } \\
\text { chromosomal cpe }\end{array}$ & [30] \\
\hline NCTCI0239 & $\begin{array}{l}\text { Food poisoning type } \mathrm{A} \text { isolate carrying a } \\
\text { chromosomal cpe }\end{array}$ & {$[30]$} \\
\hline $\mathrm{Cl} 1841$ & $\begin{array}{l}\text { Food poisoning type } \mathrm{A} \text { isolate carrying a } \\
\text { chromosomal cpe }\end{array}$ & {$[30]$} \\
\hline 13 & Type A, laboratory strain & {$[18]$} \\
\hline $\mathrm{IHIOI}$ & spoOA mutant derivative of SMIOI & [19] \\
\hline DRIOI & ssp3 mutant derivative of SMIOI & This study \\
\hline \multicolumn{3}{|l|}{ Plasmids } \\
\hline PJIR 75I & $C$. perfringens $-E$. coli shuttle vector $; \mathrm{Em}^{r}$ & {$[25]$} \\
\hline PJIR 418 & C. perfringens $-E$. coli shuttle vector $; \mathrm{Cm}^{r}$, Em ${ }^{r}$ & {$[31]$} \\
\hline PMRSI04 & $\begin{array}{l}\text { Suicidal plasmid, no origin of replication for } \\
\text { Clostridia; Emr }\end{array}$ & [19] \\
\hline pSMIO4 & cpe-gusA in pJIR750; $\mathrm{Cm}^{r}$ & {$[26]$} \\
\hline pSM242 & sigK-gusA fusion in pJIR750; $\mathrm{Cm}^{r}$ & S.B. Melville \\
\hline PMRSI 27 & sigK-gusA fusion in pJIR75I; Em ${ }^{r}$ & This study \\
\hline PMRSI 30 & PJIR75I carrying promoter-less gusA; Emr & This study \\
\hline $\mathrm{pBH} 2$ & $\begin{array}{l}\text { ssp3 and } 1.9-\mathrm{kb} \text { each upstream and } \\
\text { downstream region cloned into } \mathrm{PCR}^{{ }^{\circledR}-\mathrm{XL}-} \\
\text { TOPO }\end{array}$ & This study \\
\hline PSGII & ssp / promoter in $\mathrm{PCR}^{\circledR}{ }^{\circledR}-\mathrm{XL}-\mathrm{TOPO}{ }^{\circledR}$ & This study \\
\hline PSG 12 & ssp/-gusA in PMRSI27; Em ${ }^{r}$ & This study \\
\hline PDRI3 & $\begin{array}{l}\text { ssp2 and } 1.4-k b \text { each upstream and } \\
\text { downstream region cloned into } P C{ }^{\circledR}{ }_{-}-X L- \\
\text { TOPO }{ }^{\circledR} \text {. }\end{array}$ & This study \\
\hline pDRI4 & Nrul site incorporated into ssp2 in pDR 13 & This study \\
\hline pDRI7 & ssp3 with its promoter in $\mathrm{PCR}^{\circledR}{ }_{-}-\mathrm{XL}-\mathrm{TOPO}{ }^{\circledR}$ & This study \\
\hline PDRI8 & ssp3 with its promoter in pJIR75I; Em ${ }^{r}$ & This study \\
\hline PSG2I & ssp2 promoter in $\mathrm{PCR}^{\circledR}$-XL-TOPO ${ }^{\circledR}$ & This study \\
\hline PSG22 & ssp2-gusA in pMRSI27; Emr & This study \\
\hline pDR26 & ssp2::catP in $\mathrm{PCR}^{\circledR}-\mathrm{XL}-\mathrm{TOPO}^{\circledR}$ & This study \\
\hline pDR27 & ssp2::catP in pMRSI04; EmrCmr & This study \\
\hline pSG3I & ssp3 promoter in $\mathrm{PCR}^{\circledR}{ }_{-} \mathrm{XL}-\mathrm{TOPO}{ }^{\circledR}$ & This study \\
\hline PDR 31 & $\begin{array}{l}\text { ssp } I \text { and } I .5-\mathrm{kb} \text { each upstream and } \\
\text { downstream region cloned into } \mathrm{PCR}^{{ }} \mathrm{X} \mathrm{X} \text { - } \\
\text { TOPO }{ }^{\circledR} \text {. }\end{array}$ & This study \\
\hline pSG32 & ssp3-gusA in pMRSI27; Em & This study \\
\hline PMRS60 & Hpal site incorporated into ssp3 in $\mathrm{pBH} 2$ & This study \\
\hline PMRS6I & ssp3::catP in pMRS60; $\mathrm{Cm}^{r} \mathrm{Km}^{\mathrm{r}}$ & This study \\
\hline PMRS62 & ssp3::catP in pMRSI04; Emr Cm ${ }^{r}$ & This study \\
\hline pDR6I & Nrul site incorporated into ssp / in pDR3 I & This study \\
\hline pDR62 & ssp I::catP in pDR6I; CmrKm $\mathrm{m}^{r}$ & This study \\
\hline pDR63 & ssp I::catP in pMRSI04; EmrCmr & This study \\
\hline
\end{tabular}

a. Emr $, \mathrm{Cm}^{r}, \mathrm{Km}^{r}$ : resistance to erythromycin, chloramphenicol and kanamycin, respectively.

$200 \mu \mathrm{M}$ deoxynucleoside triphosphates (dNTPs) (Roche), $2.5 \mathrm{mM} \mathrm{MgCl}_{2}$, and $1 \mathrm{U}$ of Taq DNA polymerase (Fermentas) in a total volume of $50 \mu$ l. The reaction mixture was placed in a thermal cycler (Techne) for an initial period of
5 min at $94^{\circ} \mathrm{C}$, then 28 cycles, each consisting of $1 \mathrm{~min}$ at $94^{\circ} \mathrm{C}, 1 \mathrm{~min}$ at $43^{\circ} \mathrm{C}$ (for CPP7/CPP8 and CPP9/CPP10) or $44^{\circ} \mathrm{C}$ (for CPP11/CPP34), $1 \mathrm{~min}$ at $72^{\circ} \mathrm{C}$, and followed by an additional period of extension for $10 \mathrm{~min}$ at 
Table 2: Primers used in this study

\begin{tabular}{|c|c|c|c|c|}
\hline Primers name & Primer Sequence ${ }^{\mathrm{a}}$ & Position ${ }^{b}$ & Gene & $U_{s e}^{c}$ \\
\hline CPP 7 & $\begin{array}{l}5^{\prime} \\
\text { GCTTACAAATTACCAA } \\
\text { AGCC } 3^{\prime}\end{array}$ & -36 to -17 & sspl & $\mathrm{PCR}, \mathrm{Se}$ \\
\hline CPP 8 & $\begin{array}{l}5^{\prime} \\
\text { CAGTATTAGCGAAAGG } \\
\text { TTTG } 3^{\prime}\end{array}$ & 83 to 202 & sspl & PCR, Se \\
\hline CPP 9 & $\begin{array}{l}5^{\prime} \\
\text { CTCCTATAATTCCCTC } \\
\text { TCAT } 3^{\prime}\end{array}$ & -105 to -86 & $\operatorname{ssp} 2$ & $\mathrm{PCR}, \mathrm{Se}$ \\
\hline CPPIO & $\begin{array}{l}5^{\prime} \\
\text { GTAGACTTTAATAGGT } \\
\text { TCAGG 3' }\end{array}$ & 180 to 200 & $\operatorname{ssp} 2$ & $\mathrm{PCR}, \mathrm{Se}$ \\
\hline CPPII & $\begin{array}{l}5^{\prime} \\
\text { CTGCACATCATAATAT } \\
\text { TGAAAGG 3' }\end{array}$ & -80 to -58 & ssp3 & PCR, Se \\
\hline CPP 13 & $\begin{array}{l}\text { 5' } \\
\text { GAGGGTCCTATTGTAG } \\
\text { GAGGATT 3' }\end{array}$ & -2010 to -1888 & $\operatorname{ssp} 3$ & MP, SB \\
\hline CPP 16 & $\begin{array}{l}5^{\prime} \\
\text { ATAGCAGGAGGAGCTA } \\
\text { TTCCAC } 3^{\prime}\end{array}$ & 2099 to 2120 & $\operatorname{ssp} 3$ & MP, SB \\
\hline CPP 2I & $\begin{array}{l}5^{\prime} \\
\text { CGGAGACCTTAGCTCA } \\
\text { AGTTAACGCGGAAGCG } \\
\text { TTGGTGGAG 3' }\end{array}$ & 95 to 135 & $\operatorname{ssp} 3$ & SDM \\
\hline CPP 22 & $\begin{array}{l}5^{\prime} \\
\text { CTCCACCAACGCTTCC } \\
\text { GCGTTAACTTGAGCTA } \\
\text { AGGTCTCCG 3' }\end{array}$ & 95 to 135 & $\operatorname{ssp} 3$ & SDM \\
\hline CPP 34 & $\begin{array}{l}\text { 5' } \\
\text { GCTATGGATCTTATGG } \\
\text { AAGG 3' }\end{array}$ & 423 to 442 & $\operatorname{ssp} 3$ & PCR, Se \\
\hline CPP37 & $\begin{array}{l}\text { 5' } \\
\text { CGGCTTCTAGCACATC } \\
\text { TTCT 3' }\end{array}$ & -1662 to -1593 & $\operatorname{ssp} 2$ & MP, SB \\
\hline CPP38 & $\begin{array}{l}5^{\prime} \\
\text { TATGTGGAGCAGGAAT } \\
\text { TGCC } 3^{\prime}\end{array}$ & 1449 to 1469 & $\operatorname{ssp} 2$ & MP, SB \\
\hline CPP47 & $\begin{array}{l}\text { 5'GTACCATTCTCAGAT } \\
\text { TACAATGTCGCGAAGC } \\
\text { GTTGGTGGAGAAATGG } \\
3^{\prime}\end{array}$ & 73 to 113 & $\operatorname{ssp} 2$ & SDM \\
\hline CPP48 & $\begin{array}{l}5^{\prime} \\
\text { CCATTTCTCCACCAAC } \\
\text { GCTTCGCGACATTGTA } \\
\text { ATCTGAGAATGGTAC 3' }\end{array}$ & 73 to 113 & $\operatorname{ssp} 2$ & SDM \\
\hline CPP45 & $\begin{array}{l}5^{\prime} \\
\text { CCAGGAAAGTATGGAC } \\
\text { AAGC }\end{array}$ & -1564 to -1544 & sspl & MP \\
\hline CPPI39 & $\begin{array}{l}5^{\prime} \\
\text { CCTCACCATTATCCTC } \\
\text { TACAAG 3' }\end{array}$ & 1782 to 1802 & sspl & MP \\
\hline CPPI04 & $\begin{array}{l}5^{\prime} \\
\text { GCTAGAGAATTAGGGG } \\
\text { TACCTCGCGACCTAAG } \\
\text { TTCAAGACAA 3' }\end{array}$ & 60 to 116 & sspl & SDM \\
\hline CPPI05 & $\begin{array}{l}5^{\prime} \\
\text { TTGTCTTGAACTTAGG } \\
\text { TCGCGAGGTACCCCTA } \\
\text { ATTCTCTAGC 3' }\end{array}$ & 60 to 116 & sspl & SDM \\
\hline CPP 57 & $\begin{array}{l}\text { 5' } \\
\text { GCGTCGACCTGTTTGA } \\
\text { GCTTTTTTC } 3^{\prime}\end{array}$ & -200 to -213 & ssp3 promoter & GUS \\
\hline
\end{tabular}


Table 2: Primers used in this study (Continued)

\begin{tabular}{|c|c|c|c|c|}
\hline CPP 58 & $\begin{array}{l}5^{\prime} \\
\text { GCTGCAGCCTGGAACT } \\
\text { AAATGTTGT } 3^{\prime}\end{array}$ & 3 to 21 & ssp3 promoter & GUS \\
\hline CPP 63 & $\begin{array}{l}5^{\prime} \\
\text { GCGTCGACTAGGTGCA } \\
\text { GAAGC } 3^{\prime}\end{array}$ & -219 to -203 & ssp / promoter & GUS \\
\hline CPP 64 & $\begin{array}{l}5^{\prime} \\
\text { GCTGCAGCTGGAACTA } \\
\text { ATGATTTTGAC 3' }\end{array}$ & 3 to 21 & ssp / promoter & GUS \\
\hline CPP 65 & $\begin{array}{l}5^{\prime} \\
\text { GCGTCGACGGAACTAA } \\
\text { AGCTAAATTTGG 3' }\end{array}$ & -238 to -223 & ssp2 promoter & GUS \\
\hline CPP 66 & $\begin{array}{l}5^{\prime} \\
\text { GCTGCAGGCTTCTGGT } \\
\text { ACTAAATGTTGTG 3' }\end{array}$ & 3 to 25 & ssp2 promoter & GUS \\
\hline
\end{tabular}

a Restriction sites are marked by underlining.

bThe nucleotide position numbering begins from the first codon and refers to the relevant position within the respective ssp gene sequence [18]. cPCR, polymerase chain reaction; Se, sequencing studies; MP, construction of mutator plasmid; SB, southern blot analysis; SDM, site-directed muatgenesis. GUS, construction of plasmid for $\beta$-glucuronidase assay.

$72^{\circ} \mathrm{C}$. After PCR, the presence of an amplified product was analyzed by subjecting an aliquot of each PCR sample to agarose $(1.5 \%)$ gel electrophoresis.

\section{Cloning and sequencing of the ssp-containing fragments from various cpe-positive isolates}

The DNA fragment containing ssp ORFs and an 200 bp upstream sequence from each of five $C$. perfringens chromosomal cpe isolates was amplified by PCR as described above. These PCR products were then cloned into $\mathrm{pCR}^{\circledR}$ $\mathrm{XL}^{-T O P O}{ }^{\circledast}$ vector using the TOPO ${ }^{\circledast} \mathrm{XL}$ cloning kit (Invitrogen). Both strands of the ssp-containing DNA insert present in recombinant $\mathrm{pCR}^{\circledR}$-XL-TOPO ${ }^{\circledR}$ plasmid was then sequenced using M13 forward and reverse primers.

\section{Construction of gusA-fusion plasmids and $\beta$-glucuronidase assay}

The gusA reporter vector pSM242 (obtained from Dr. Melville as a gift), is a derivative of an E. coli-C. perfringens shuttle vector pJIR750 [25], encoding chloramphenicol resistance $\left(\mathrm{Cm}^{\mathrm{r}}\right)$, contains the following features: i) four tandem terminators to minimize vector-based transcription, ii) multicloning sites located upstream of a promoterless cpe-gusA fusion, iii) the ribosome binding site and the first 13 amino acids of the cpe gene coding region to provide efficient translation [26] and iv) the E. coli gusA [27] as a transcriptional reporter element. Since our C. perfringens spo0A mutant already contained $\mathrm{Cm}^{\mathrm{r}}$ marker, for our study we first constructed an erythromycin resistant $\left(\mathrm{Em}^{\mathrm{r}}\right)$ derivative of pSM242. An $2.5-\mathrm{kb}$ EcoRI-HindIII fragment of pSM242 was cloned into EcoRI/HindIII sites of an E. coli-C. perfringens shuttle vector pJIR751 [25], which encodes Em ${ }^{\mathrm{r}}$, to create pMRS127.

The PCR amplified product ( 200-bp) carrying the upstream region of each $s s p$ was first cloned into $\mathrm{pCR}^{\circledR}$-XLTOPO $^{\circledast}$ vector using TOPO $^{\circledR}$-XL cloning kit (Invitrogen).
Briefly, the DNA fragment carrying the promoter region of each of $s s p 1,2$ or 3 from SM101 (a food poisoning isolate carrying cpe on the chromosome) was amplified by PCR using primers CPP63/CPP64, CPP65/CPP66 and CPP57/ CPP58, respectively (Table 2). The SalI site was incorporated in the forward and PstI site in the reverse primers of each primer pairs. These PCR products were then cloned into $\mathrm{pCR}^{\circledR}$-XL-TOPO ${ }^{\circledR}$ vector. The SalI-PstI fragments carrying the promoter regions of $s s p 1,2$ or 3 from pCR $^{\circledR}$-XL$\mathrm{TOPO}^{\circledast}$ clones were then re-cloned into the SalI/PstI sites of pMRS127 to create ssp1-, 2- or 3-gusA fusion constructs, pSG12, pSG22 or pSG32, respectively. As a negative control, pMRS130 carrying promoter-less gusA was constructed by cloning of XbaI-SacI fragment from pSM104 [26] into the XbaI/SacI sites of pJIR751. These plasmids were then introduced into C. perfringens wild-type SM101 or spoOA mutant IH101 by electroporation [24] and Em ${ }^{\mathrm{r}}$ transformants were selected. The SM101 and IH101 transformants carrying ssp-gusA fusions or promoter-less gusA were grown in vegetative and sporulation conditions and tested for $\beta$-glucuronidase (GUS) activity as previously described $[26,28]$.

\section{Extraction of SASPs and Western blotting}

C. perfringens SASP was extracted using the protocol as previously described [29]. Briefly, sporulating cells of $C$. perfringens were sonicated and then centrifuged. The spores were washed several times with distilled water and lyophilized. The dried spores were subjected to dry rupture in a dental amalgamator (Wig-L-Bug) using $0.1 \mathrm{~g}$ of glass beads as an abrasive. The spore powder was resuspended in 3\% acetic acid solution and then subjected to dialysis (Spectr/por ${ }^{\circledR} 3$, MWCO- 3,500, Spectrum laboratories) against $1 \%$ acetic acid solution at $4{ }^{\circ} \mathrm{C}$ for at least 24 h. The sample was lyophilized and used for analysis by polyacrylamide gel electrophoresis at low $\mathrm{pH}$ as previously described [29]. The gel was run at $20 \mathrm{~mA}$ with the 
appropriate electrode polarity since SASPs are positively charged and hence run towards the cathode. The gel was stained with commassie brilliant blue (Bio-Rad) or transferred to a nitrocellulose membrane for Western blotting. The blot was probed with antibodies against B. subtilis SspC $[13,29]$ and developed for chemiluminescence detection (Pierce) to identify immunoreactive species.

\section{Construction of mutator plasmids for ssp I, 2 and 3} ssp1 mutator plasmid: A 3306-bp DNA fragment containing ssp1 ORF and 1.5-kb each upstream and downstream region was PCR amplified from genomic DNA of SM101 using primers CPP45 and CPP139 (Table 2) and cloned into $\mathrm{pCR}^{\circledR}-\mathrm{XL}^{-T O P O}{ }^{\circledR}$ (Invitrogen) to create pDR31. The 15-bp (nucleotides 80-94 from ATG) internal deletion as well as a unique NruI site was incorporated in ssp1 in pDR31 by site-directed mutagenesis using Quick Change Mutagenesis System (Qiagen) using primers CPP104 and CPP105 to create pDR61. Plasmid pDR62 was construced by cloning a 1.3-kb SmaI-NaeI fragment of pJIR418, carrying chloramphenicol resistance marker catP, into NruI site of pDR61. The ssp1 mutator plasmid, pDR63, was then constructed by re-cloning the BamHI-XhoI fragment containing $\Delta s s p 1:: c a t P$ allele, from pDR62 into BamHI/SalI sites of suicidal plasmid pMRS104.

ssp2 mutator plasmid: A 3081-bp DNA fragment containing ssp2 ORF and 1.4-kb each upstream and downstream region was PCR amplified from genomic DNA of SM101 using primers CPP37 and CPP38 (Table 2) and cloned into $\mathrm{pCR}^{\circledR}-\mathrm{XL}-\mathrm{TOPO}^{\circledast}$ (Invitrogen) to create $\mathrm{pDR} 13$. Plasmid pDR14 was constructed by deleting 15-bp (nucleotides 102-115 from ATG) internal ssp2 fragment as well as incorporating a unique NruI site in ssp2 present in pDR13 by site-directed mutagenesis using Quick Change Mutagenesis System (Qiagen) using primers CPP47 and CPP48. A 1.3-kb SmaI-NaeI fragment of pJIR418, carrying chloramphenicol resistance marker catP, was cloned into NruI site of pDR14 to create plasmid pDR26. The ssp2 mutator plasmid pDR27 was then constructed by re-cloning the BamHI-XhoI fragment containing $\Delta s s p 2:$ :catP allele, from pDR62 into BamHI/SalI sites of suicidal plasmid pMRS104.

ssp3 mutator plasmid: A 4129-bp DNA fragment, carrying the ssp3 ORF and $~ 1.9-\mathrm{kb}$ each upstream and downstream region, was PCR amplified from genomic DNA of SM101 using primers CPP13 and CPP16 (Table 2). This PCR fragment was cloned into $\mathrm{PCR}^{\circledR}$-XL-TOPO ${ }^{\circledast}$ (Invitrogen) to create the plasmid $\mathrm{pBH} 2$. A unique $H p a \mathrm{I}$ restriction site was incorporated into the ssp3 ORF (at position 117 from ATG) present in $\mathrm{pBH} 2$ by site-directed mutagenesis using Quick Change Mutagenesis System (Qiagen) using primers CPP21 and CPP22 to create pMRS60. The catP gene was then inserted into the unique $H p a$ I site located within the ssp3 ORF in pMRS60 by digesting pMRS60 with HpaI and ligating with a 1.3-kb SmaI-NaeI fragment containing the catP gene from pJIR418, to create pMRS61. The ssp3 mutator plasmid pMRS62 was then constructed by recloning the KpnI-XhoI fragment of pMRS61 into KpnI/SalI sites of suicidal plasmid pMRS104.

\section{Isolation of ssp knock-out mutants}

The mutator plasmids pDR63, pDR27 and pMRS62 were used to transform, by electroporation [24], C. perfringens isolate SM101 to Erythromycin (Em) $(50 \mu \mathrm{g} / \mathrm{ml})$ and Chloramphenicol $(\mathrm{Cm})(20 \mu \mathrm{g} / \mathrm{ml})$ resistance. One transformant for each plasmid was grown in TGY broth without any antibiotics and colonies sensitive to Em, but resistant to $\mathrm{Cm}$ were selected as previously described $[3,19]$.

\section{Southern blot analysis}

The ssp3-specific DNA probe was prepared using a 4129bp DNA fragment, carrying ssp3 and $\sim 1.9-\mathrm{kb}$ each upstream and downstream region. This DNA fragment was amplified by PCR from genomic DNA of SM101 using primers CPP13 and CPP16 (Table 2). The catP probe was produced using a 517-bp EcoRV-HpaI fragment, containing internal catP gene sequences, from pJIR418. These ssp3- and catP-containing DNA fragments were labeled using a Random Primed DNA Labeling system (Roche). Total DNA from wild type and ssp3 mutant strains was digested with HpaI and two identical Southern blots were prepared using this digested DNA and hybridized, separately, with probes specific for the ssp3 or catP. The hybridized probe was detected using a DIG-chemiluminescence detection system utilizing CSPD $^{\circledast}$ [disodium 3-(4-methoxyspiro[1]-4-yl)phenyl phosphate] ready-touse substrate (Roche) as previously described $[3,4]$.

\section{CPE Western blot analysis}

C. perfringens strains grown in DS or FTG medium were sonicated until $>95 \%$ of all cells were lysed (lysis was continuously monitored by phase-contrast microscopy). After sonication, each culture lysate was analyzed for the presence of CPE by Western blot analysis using a CPE antibody as previously described [4,22].

\section{Determination of $D$ values for $C$. perfringens spores}

The heat sensitivities of $C$. perfringens spores was determined as described previously [4]. Briefly, DS medium cultures prepared and grown for $24 \mathrm{~h}$ as described above were heat shocked at $75^{\circ} \mathrm{C}$ for 20 min which killed the remaining vegetative cells and facilitated spore germination. A $0.1 \mathrm{ml}$ aliquot of each heat-shocked DS medium culture was then serially diluted with sterile FTG medium and each dilution was plated onto Brain Heart Infusion (BHI) agar plates to establish the number of viable spores 
per milliliter of DS medium culture at the start of heating (i.e., the zero time point of the experiment).

The remainder of each heat-shocked DS medium culture was then heated at $100^{\circ} \mathrm{C}$ for time period ranging from 30 min to $90 \mathrm{~min}$. At each time point, a $0.1-\mathrm{ml}$ aliquot was withdrawn and diluted with FTG broth. The dilutions were then plated on BHI agar plates, which were incubated anaerobically at $37^{\circ} \mathrm{C}$ for $24 \mathrm{~h}$. Colonies which developed from germinated spores that survived heating were counted to determine the number of viable colony forming unit (CFU) that were present per milliliter of each heated DS medium culture at each time point. The CFU values were then graphed to determine decimal reduction value ( $D$ value) (i.e., the time that a culture had to be kept at a given temperature to obtain a $90 \%$ reduction in viable cell numbers) for spores of each isolate tested.

\section{Assay of SASP-nucleic acid binding}

The binding of $C$. perfringens SASPs to nucleic acid was assessed by measuring the ability of SASP to protect nucleic acid from nuclease digestion as previously described [20]. Briefly, SASPs was prepared from C. perfringens SM101 spores as described above and quantified using the Bradford protein assay kit (Bio-Rad). $3 \mu \mathrm{g}$ of plasmid pJIR751 DNA was incubated in $25 \mu \mathrm{l}$ of $10 \mathrm{mM}$ Tris-acetate (pH 7.0) -1 mM EDTA with $3 \mu \mathrm{g}$ of SASPs (1:1 ratio). After $1 \mathrm{~h}$ at $37^{\circ} \mathrm{C}, 3 \mu \mathrm{l}$ of DNase I buffer was added, followed by $2 \mu \mathrm{l}$ of DNase I (Farmentas). The solution was incubated a further $10 \mathrm{~min}$ at $37^{\circ} \mathrm{C}$, and then $100 \mu \mathrm{l}$ of $1.25 \%$ sodium dodecyl sulfate (SDS)-25 mM EDTA was added, followed by $13 \mu \mathrm{l}$ of $5 \mathrm{M} \mathrm{NaCl}$ and $350 \mu$ lof ethanol to precipitate the DNA. The precipitated DNA was dissolved in $10 \mu \mathrm{l}$ of water and subjected to agarose $(1.5 \%)$ gel electrophoresis. The presence or absence of DNA was observed under UV illumination after staining with ethidium bromide.

\section{Statistical analyses}

Statistical analyses were performed with student's $t$ test.

\section{Authors' contributions}

DR carried out most of the experiments, and participated in the discussions on the study design, analyses and interpretation of the data, and in the writing of the manuscript. MW carried out experiments related to isolation of SASPs from C. perfringens. PS participated as a consultant and hosted MW in his laboratory to learn basic techniques for isolation of SASPs. MRS, as a principal author of this manuscript, participated in the planning and designing of the experiments and writing of the manuscript.

\section{Acknowledgements}

This research was supported by a grant from the N. L. Tartar Foundation of Oregon State University and by USDA grant 2002-0228I from the Ensuring Food Safety Research Program (all to M.R.S). We are grateful to
Dr. B. A. McClane, University of Pittsburgh School of Medicine, for providing us with CPE antibody. We thank Nahid Mahfuz for her technical assistance.

\section{References}

I. McClane BA: Clostridium perfringens. In Food microbiology: fundamentals and frontiers 2 nd edition. Edited by: M. P. Doyle LRBTJM. Washington, D.C., ASM Press; 2001:35I-372.

2. McDonel JL: Toxins of Clostridium perfringens type A, B, C, D, and E. In Pharmacology of bacterial toxins Edited by: Drews FDH. Oxford, United Kingdom, Pergamon Press; 1986:477-517.

3. Sarker MR, Carman RJ, McClane BA: Inactivation of the gene (cpe) encoding Clostridium perfringens enterotoxin eliminates the ability of two cpe-positive $C$. perfringens type $A$ human gastrointestinal disease isolates to affect rabbit ileal loops. Mol Microbiol 1999, 33:946-958.

4. Sarker MR, Shivers RP, Sparks SG, Juneja VK, McClane BA: Comparative experiments to examine the effects of heating on vegetative cells and spores of Clostridium perfringens isolates carrying plasmid genes versus chromosomal enterotoxin genes. Appl Environ Microbiol 2000, 66:3234-3240.

5. Nicholson WL, Munakata N, Horneck G, Melosh HJ, Setlow P: Resistance of Bacillus endospores to extreme terrestrial and extraterrestrial environments. Microbiol Mol Biol Rev 2000, 64:548-572.

6. Setlow P: Mechanisms for the prevention of damage to DNA in spores of Bacillus species. Ann Rev Microbiol 1995, 49:29-54.

7. Setlow P: Small, acid-soluble proteins of Bacillus species: structure, synthesis, genetics, function and degradation. Ann Rev Microbiol 1988, 42:319-338.

8. Fairhead H, Setlow B, Setlow P: Prevention of DNA damage in spores and in vitro by small, acid-soluble proteins from Bacillus subtilis. J Bacteriol 1993, I75:1367-1374.

9. Mason JM, Setlow P: Essential role of small, acid-soluble spore proteins in resistance of Bacillus subtilis spores to $U V$ light. J Bacteriol 1986, 167:174-178.

10. Setlow B, Setlow P: Binding of small, acid-soluble spore proteins to DNA plays a significant role in the resistance of Bacillus subtilis spores to hydrogen peroxide. Appl Environ Microbiol 1993, 59:3418-3423.

II. Setlow B, Setlow CA, Setlow P: Killing bacterial spores by organic hydroperoxidases. J Ind Microbiol I997, 18:384-388.

12. Cabrera-Mattinez RM, Mason JM, Setlow B, Waites WM, Setlow P: Purification and amino acid sequence of two small, acid-soluble proteins from Clostridium bifermentans spores. FEMS Microbiol Lett 1989, 6 I:139-144.

13. Granum PE, Richardson M, Bolm H: Isolation and amino acid sequence of an acid soluble spore protein from Clostridium perfringens. FEMS Microbiol Lett 1987, 42:225-230.

14. Setlow $P$, Waites WM: identification of several unique low molecular weight basic proteins in dormant spores of Clostridium bifermentans and their degradation during spore germination. J Bacteriol 1976, 127:1015-1017.

15. Cabrera-Martine RM, Setlow P: Cloning and nucleotide sequence of three genes coding for small, acid-soluble proteins of Clostridium perfringens spores. FEMS Microbiol Lett 1991, 77:127-132.

16. Holck A, Bolm H, Granum PE: Cloning and sequencing of the genes encoding acid-soluble spore proteins from Clostridium perfringens. Gene 1990, 92: I07-III.

17. Shimizu T, Ohtani K, Hirakawa H, Ohshima K, Yamashita A, Shiba T, Ogasawara N, Hattori M, Kuhara S, Hayashi H: Complete genome sequence of Clostridium perfringens, an anaerobic flesheater. Proc Natl Acad Sci U S A 2002, 99:996- I00 I. Epub 2002 Jan I 5.

18. Huang IH, Waters M, Grau RR, Sarker MR: Disruption of the gene (spo0A) encoding sporulation transcription factor blocks endospore formation and enterotoxin production in enterotoxigenic Clostridium perfringens type A. FEMS Microbiol Lett 2004, 233:233-240.

19. Setlow B, Dongxu S, Setlow P: Interaction between DNA and alpha/beta-type small. acid-soluble spore proteins: a new class of DNA-binding protein. J Bacteriol 1992, 174:23 I2-2322.

20. Awad MM, Bryant AE, Stevens DL, Rood Jl: Virulence studies on chromosomal alpha-toxin and theta-toxin mutants constructed by allelic exchange provide genetic evidence for the 
essential role of alpha-toxin in Clostridium perfringensmediated gas gangrene. Mol Microbiol 1995, 15:191-202.

21. Kokai-Kun JF, Songer JG, Czeczulin JR, Chen F, McClane BA: Comparison of Western immunoblots and gene detection assays for identification of potentially enterotoxigenic isolates of Clostridium perfringens. J Clin Microbiol 1994, 32:2533-2539.

22. Collie RE, Kokai-kun JF, McClane BA: Phenotypic characterization of enteropathogenic Clostridium perfringens isolates from non-food-borne human gastrointestinal diseases. Anaerobes 1998, 4:69-79.

23. Czeczulin JR, Collie RE, McClane BA: Regulated expression of Clostridium perfringens enterotoxin in naturally cpe-negative type A, B, and C isolates of C. perfringens. Infect Immun 1996, 64:3301-3309.

24. Bannam TL, Rood Jl: Clostridium perfringens-Escherichia coli shuttle vectors that carry single antibiotic resistance determinants. Plasmid 1993, 29:233-235.

25. Melville SB, Labbe RG, Sonenshein AL: Expression from the Clostridium perfringens cpe promoter in Clostridium perfringens and Bacillus subtilis. Infect Immun 1994, 62:5550-5558.

26. Jefferson RA, Burges SM, Hirsh D: b-Glucuronidase from E. coli as a gene-fusion marker. Proc Natl Acad Sci U S A 1986, 83:8447-845।.

27. Zaho $Y$, Melville SB: Identifaction and characterization of sporulation-dependent promoter upstream of the enterotoxin gene (cpe) of Clostridium perfringens. J Bacteriol 1998, 180:136-142.

28. Nicholson WL, Setlow P: Sporulation, germination and outgrowth. In Molecular biological methods for Bacillus Edited by: Cutting CRHSM. Chichester, John Wiley and Sons; 1990:391-450.

29. Collie RE, McClane BA: Evidence that the enterotoxin gene can be episomal in Clostridium perfringens isolates associated with non-food-borne human gastrointestinal diseases. J Clin Microbiol 1998, 36:30-36.

30. Sloan J, Warner TA, Scott PT, Bannam TL, Berryman DI, Rood Jl: Construction of a sequenced Clostridium perfringensEscherichia coli shuttle plasmid. Plasmid 1992, 27:207-219.
Publish with Bio Med Central and every scientist can read your work free of charge

"BioMed Central will be the most significant development for disseminating the results of biomedical research in our lifetime. "

Sir Paul Nurse, Cancer Research UK

Your research papers will be:

- available free of charge to the entire biomedical community

- peer reviewed and published immediately upon acceptance

- cited in PubMed and archived on PubMed Central

- yours - you keep the copyright 